\title{
Aspirations and human development interventions
}

\author{
Ina Conradie and Ingrid Robeyns
}

\begin{abstract}
What role can aspirations play in small-scale human development interventions? In this paper, we contribute to answering that question with both conceptual and empirical work. Aspirations can play at least two roles in small-scale human development interventions: the capabilities-selecting role and the agencyunlocking role. While aspirations also face the challenge of adaptation to adverse circumstances and unjust social structures, we argue that this challenge can be met by embedding the formulation and expression of aspirations within a setting of public discussion and awareness-raising activities, and that adaptation can be further countered by including a commitment to action. We then report on field research done in Khayelitsha, a township in Cape Town, South Africa, where a group of women went through a process of voicing, examining, and then realizing their aspirations. The action research confirms our theoretical hypotheses. We also do not find any evidence of adaptation of the women's aspirations, and argue that the absence of such adaptation might be a result of active capability selection, reflection, deliberation, and the exercise of agency throughout the action research programme.
\end{abstract}

\section{Introduction}

Among development scholars and development think-tanks there is an increasing awareness that low aspirations may in some contexts constitute part of what poverty is, and hence that working on aspirations of the poor can play an important role in an anti-poverty strategy (for example, Ray, 2003; Appadurai, 2004; Bernard et al., 2008; Ibrahim, 2011). ${ }^{1}$ In this paper we aim to contribute to that emerging literature from within the human development paradigm. More specifically, we aim at advancing our understanding of smallscale human development interventions (i.e. development interventions focused on capability enhancement at the grass-roots level in a limited context), by analysing to what extent aspirations can be a useful tool in the practice of human development interventions. Our analysis is in part built on conceptual work and the development of theoretical hypotheses, and in part on empirical work in Khayelitsha, a township in Cape Town, South Africa. ${ }^{2}$

We will proceed as follows. In the next section we discuss the concepts that we will use. In the third section we theorize the role aspirations can play in human development interventions, and also pay attention to the problem of 
adaptation. The fourth to sixth sections report on the field research done in Khayelitsha, where a group of women was assisted in a process of exploring their aspirations and working on them. Our findings confirm the roles of aspirations that we hypothesized in the theoretical part, and also show that no evidence has been found of adaption of aspirations to adverse circumstances. In the final section we ask what we can learn from this particular action research for the role that aspirations can play in human development interventions.

\section{Conceptual groundwork}

Before we can reflect on the role aspirations can play in small-scale human development interventions, some basic conceptual groundwork is needed.

\section{Human development interventions}

Human development interventions are development interventions aimed at capabilities enhancement, while also aiming at strengthening other important human values, such as democracy and people's agency. Capabilities are real opportunities people have for states of being and doing. Examples of these states of being and doing (which are called functionings) are being healthy, being well nourished, being educated, being employed, being part of a supporting social network, and so forth (Alkire, 2005; Robeyns, 2005a; Sen, 1999).

A development intervention is a result-oriented action aimed at improving people's quality of life. The agents initiating the development intervention can be insiders or outsiders, civil society institutions, governments, individuals or small groups. Interventions and strategies are closely related notions, except for the fact that a strategy may not have to be executed (it can be a plan one holds in one's pocket just in case one needs it) whereas an intervention is a strategy that is being executed.

Development interventions can be at different levels of scope and aggregationfrom small-scale intervention to interventions that affect the entire country or region. An example of the latter could be a macro-economic policy intervention introduced by the national government, but also a people-based revolution aiming at equal political rights and socio-economic opportunities for all. Smallscale development interventions have already received considerable attention in the human development literature (for example, Alkire, 2002, pp. 233-296; Tiwari and Ibrahim, 2012).

Development itself is a contested idea and many influential views on development do not focus directly on human beings. By labelling development interventions, more specifically human development interventions, we want to stress that we are interested only in those interventions that aim at the expansion of human capabilities.

\section{Tools from the capability toolbox}

The capability approach, which is the theoretical framework supporting the notion of human development, is an approach that is used for many different 
purposes, from abstract philosophical reflections to quantitative empirical work. When we are reflecting on strategies and interventions, it helps to think of the capability approach as a toolbox that contains a variety of theoretical and methodological tools, some of which are useful for one task, while some are more useful for another. For present purposes, two tools from the capability toolbox are helpful: capability inputs, and capability obstacles (Robeyns, 2010, pp. 251-254).

Capability inputs are the means that are needed to realize certain capabilities. These means can be material resources (especially money or commodities), but also other types of inputs, such as natural resources (e.g. air, water, fertile land) or relationship goods (e.g. social capital or family capital). Capability obstacles are aspects that need to be removed, eliminated or combated in order to help the corresponding capability to be realized. For example, if there is a local social norm that women should not seek employment, then this is an obstacle to women's capability to be employed.

If an intervention aims at expanding capability $x$, then we will need to know which capability inputs are important for $x$, and which obstacles are preventing $x$ from fully emerging. Finding out which are the corresponding inputs and obstacles to a certain capability is crucial for human development interventions: without this knowledge, it would not be clear how to proceed.

\section{Aspirations}

In development studies, the concept of 'aspirations' closely follows common-sense language. According to the online Oxford Dictionary, 'aspirations are the hope or ambition of achieving something'. Yet an aspiration is not just a plan a person will start working out knowing with reasonable confidence that it will succeed; rather, there may be a greater element of hope and of not knowing whether it will work out.

A few things need to be noted about aspirations. First, aspirations can be expressed individually or collectively. One can ask a particular person what she aspires to. But a group of persons can also decide to formulate a collective aspiration, either because they have reason to believe that this is more fruitful, because political or organizational systems favour collective processes, or because people feel more comfortable expressing aspirations as a group than as individuals. Moreover, one has to distinguish the issue of the expression of aspirations from the issue of the ontology of aspirations. As far as the latter is concerned, it should be obvious that our aspirations are always deeply context dependent; that is, aspirations are to a significant extent influenced by our social surroundings, our upbringing, the cultural and social context in which we move, the social networks in which we are embedded, and so forth (Appadurai, 2004, p. 67).

Second, aspirations are not properties of persons simply waiting to be uncovered; rather, aspirations are formed at the moment we start to contemplate them. 
Aspirations are constructed in the process of thinking about or formulating them. As a consequence, often there may not be 'true' aspirations at a certain point in time, as a person may never have considered the question of what her aspirations would be, or may simply have resigned herself to an aspiration-less state of being. A process of becoming aware of one's aspirations, in which people are in a reflexive way invited to reflect on and express the aspirations they have, reconsider them, and possibly revise them, may both lead to the birth of new aspirations or to the discovery of latent aspirations.

Third, aspirations are dynamic. One of the contextual elements that influence aspirations is the experiences that one has had. People who have had the good fortune to experience a range of valuable encounters, activities, and achievements, may rely on these experiences in developing their own aspirations. Someone who has met a great teacher may develop the aspiration to also become a teacher. Similarly, someone who thought that a certain level of education would not be within her reach may consider it possible after she has seen one of her peers reaching that goal. But the opposite is possible too. People may have aspirations that they would, on objective grounds, most probably never reach; for example, because they might live in a highly unequal society with very limited social mobility, yet see others who have a good standard of living to which they also aspire.

Finally, we could ask how aspirations differ from the notion of preferences. There is no single answer to this question, since economists use preferences in a variety of ways. Aspirations and preferences are similar types of mental phenomena in that they tell us something about the desires and wishes of a person. Yet if we compare their most common use they do differ in several ways. First, aspirations are goals one wants to reach in the future, whereas preferences generally refer to desires or wants in the present. Second, aspirations refer to a goal one has, yet this goal need not be about one's own well-being: it could also be about commitments or moral causes. Preferences, in contrast, are generally taken to be about a person's own well-being. Thirdly, aspirations are virtually always seen as formed under influence of one's social context and through interactions with others, which is often not the case with how we use the notion of preferences.

\section{Adaptation}

For a long time, scholars have been reflecting on the fact that aspirations and preferences can be adapted, and discussing which normative and political issues adaptation raises, both theoretically as well as in the context of development (for example, Elster, 1983, Sen, 1985b, pp. 14-15; 1992, p. 55; Nussbaum, 2000; Teschl and Comim, 2005; Burchardt, 2009; Clark, 2009, 2012a, 2012b; Khader, 2009). Yet there is a variety of ways in which 'adaptation' can be understood, and the different conceptualizations have consequences for which preferences will be identified as 'adapted' and which will not. We will only focus on a subset of possible conceptualizations, namely those that are directly relevant for the topic of this paper. ${ }^{3}$ 
The conceptualization of Jon Elster (1983) referred to one particular type of adaptation, namely where not being able to fulfil a preference or realize an aspiration leads one to ultimately no longer wanting to have that preference or aspiration. This phenomenon is known as 'sour grapes'. On Elster's account, adaptation occurs at a non-conscious level, as a reaction to the painful process of cognitive dissonance that a person who cannot fulfil her unreachable desires or aspirations feels. These psychological aspects of adaptation are echoed in Sen's reference to this phenomenon, when he writes that 'considerations of "feasibility" and of "practical possibility" enter into what we dare to desire and what we are pained not to get' (1985b, p. 15).

Elster's notion of adaptive preferences or aspirations only refers to a process, and makes no reference to an objective notion of well-being. Nussbaum, in contrast, understands adaptive preferences and desires in a much more normative and perfectionist way, namely as the preferences of people not wanting to have items of her list of capabilities, whereby these preferences are deformed due to injustices, oppression, ignorance and blind habit (Nussbaum, 2000, p. 114). Applying Nussbaum's conceptualization of adaptive preferences would thus entail identifying the absence of preferences (or aspirations) for the items on her list of capabilities, but also having some evidence that these preferences have been formed under unjust circumstances.

Sen's use of adaptive preferences and desires is much less systematically worked out. He uses the term mainly for two purposes: first, to explain why people who are objectively living in a dire situation still have a much better subjective assessments of their quality of life; and second, he uses it to explain the acceptance by the underdog of his situation. As Sen (1985b, p. 14) puts it, A person who is ill-fed, undernourished, unsheltered and ill can still be high up in the scale of happiness or desire-fulfilment if he or she has learned to have "realistic" desires and to take pleasure in small mercies'. His solution to the problem of adaptive aspirations and preferences is to engage in a thorough public debate and scrutinizing of one's aspirations and preferences.

In this paper, we will rely mainly on Elster's and Sen's conceptualization of adaptation. In the action research programme that will be discussed below, we have especially used Sen's strategy to use critical scrutinizing and public debate to probe whether there is evidence of adaption. Nussbaum's strategy to deal with adaptation is different: 'A habituated preference not to have any one of the items on the list (political liberties, literacy, equal political rights, or whatever) will not count in the social choice function' (Nussbaum, 2000, p. 149). This strategy is not suited for small-scale projects, since the question is not one about social evaluation for a minimal account of social justice, but rather one about change at the grass-roots level. Change requires interaction with people of whom one may be worried that their preferences may show signs of adaption. Sen's work provides more clues on how one could go about doing just that. 
There may be an interesting relation between the adaptation of aspirations of what is feasible (Elster's and Sen's conceptualizations) and the notion of an 'aspirations gap' (Ray, 2003). The aspirations gap is 'the difference between the standard of living that is aspired to and the standard of living that one already has' (Ray, 2003, p. 3). According to Ray, this aspirations gap should be big enough for the person to want to make an effort or investment to improve her situation, but not too big so that the gap cannot be closed by any investment or effort she can make, since that would lead to too much frustration. This has consequences for how we should look at adaptation, which we have also noticed during the fieldwork in Khayelitsha. Often people adapt their aspirations to their current level of achievement. If a person then reaches the next level of achievement, he or she may adapt her aspirations upwards, and become more ambitious. The process of raising one's aspirations may in many instances only be possible in small steps, whereby aspirations shift upwards every time an aspiration has been realized, but not much earlier. The intertemporal dynamics of aspirations thus might take the shape of a staircase, whereby one goes up step by step, rather than as an elevator, which can bring us up to the highest level in one go. Thus it follows that a hypothetical aspiration that one does not wish to endorse now, since it looks entirely unfeasible, may be endorsed at a later moment in life, when the 'impossibility tag' attached to the aspiration has been dropped due to the realization of the previous (and more modest) aspirations.

\section{The role of aspirations in human development interventions}

\section{The capabilities-selecting role and the agency-unlocking role of aspirations}

What roles do aspirations play in small-scale human development interventions? There are at least two possible roles: a capabilities-selection role and an agency-unlocking role.

The capabilities-selecting role of aspirations is the role that the voicing of aspirations plays in the choice of which capabilities will matter in the human development intervention under consideration. As is well known, the capability approach argues that capabilities which 'we have reason to value' should be the object of our normative concern. But it does not tell us which capabilities are valuable, and this selection of capabilities can be done in a range of different ways (Alkire, 2008; Robeyns, 2005b).

The process of voicing and reflecting upon their aspirations is a process in which agents indicate precisely which capabilities are valuable and most relevant for them. They are unlikely to mention all capabilities that are valuable for them, since those capabilities that are already fully secured will not be part of their aspirations. For example, in a community that is not extremely poor but where large improvements in the quality of life are still possible, and where all households have a decent house and have access to good nutrition, the expressed aspirations may not refer to housing or nutrition. But from this it does not follow, obviously, that nutrition and housing are not valuable; instead what follows is that these capabilities are secured, while others (e.g. 
better education) are not. Expressed aspirations tell us which capabilities are the ones that are not yet realized, which makes the voicing of aspirations an excellent tool to decide which dimensions of well-being to target in a human development intervention.

The second role that the voicing of aspirations plays in small-scale human development interventions is that they can unlock the agency that is needed in order for the necessary changes to happen. Thus, aspirations have an agency-unlocking role too. Thinking about, talking about, and reflecting upon their aspirations, especially when this is part of a group process that creates a supportive and encouraging atmosphere, motivates people to use their latent agency to make changes in their lives, which will expand their capabilities. This would particularly apply when the reflection is linked to action. They may organize themselves in order to put the government under pressure to improve their capabilities; or they may form a self-help group which will aid them in their capability enhancement (Ibrahim, 2006).

We do not claim that voicing aspirations creates agency, but rather that the voicing of aspirations unlocks agency which is latent; that is, agency which is present but of which the agent may not be fully aware, or may so far not have been sufficiently motivated to act upon. An aspirations awareness-raising activity, in which one formulates and voices one's aspirations, can mobilize this agency so that the agency can lead to activities that are directly or indirectly capability-enhancing.

\section{The challenges posed by adaptation}

While these two roles that aspirations could play in human development interventions turn aspirations into a potentially powerful tool for such interventions, we are facing the challenge that some people's aspirations may have adapted to dire circumstances, such as deep poverty or unjust social structures. Such aspirations may therefore not be able to fulfil the two positive roles that we just laid out, and therefore adaptation may pose a serious problem for the use of aspirations as a tool for human development enhancement. If people have low aspirations, then they may believe that certain opportunities (and hence capabilities) are not available to them, while they in fact are (if only latently) available.

As a consequence, the capability approach is vulnerable to the same problems of adaptation that haunt utilitarianism (Burchardt, 2009). The capability approach postulates that we should aim at the expansion of people's beings and doings that they have reason tovalue. But the valuation process is vulnerable to people's adaptation to adverse circumstances: if people have limited ambitions, wishes or preferences, then they will be very modest when they formulate which capabilities they find valuable. The same applies to aspirations: if people have adapted aspirations, they will only have modest goals, ambitions, and hopes, even if there are much more valuable options open to them. 
How serious are the challenges posed by adaptation for the two roles that aspirations can play in small-scale human development interventions?

The first thing to note is that the most serious problem would be posed by a situation in which a person would have no aspirations at all. As the realization of one's aspirations is a step-by-step process, as we argued above, the greatest danger is in not having aspirations, and therefore giving in to resignation and apathy, rather than to be prepared to take a small step forward (Douglas, 2004, p. 87). The most important thing is to take that first step, however small-since without that first step no future steps (i.e. more ambitious aspirations) will follow.

Secondly, we have to be aware that aspirations can be distorted in two ways. A person can have adapted her aspirations to adverse circumstances, which is the phenomenon generally labelled as 'adapted aspirations'. Yet a person can also have overambitious aspirations, implying that she aspires to a life that is extremely unlikely to happen. ${ }^{4}$ Yet overambitious aspirations are always only seemingly so, since there will always be a few cases of people who, against the odds, succeed and manage to realize the unthinkable, often because of some completely unexpected events occurring. Moreover, one has to be careful with using the term 'overambitious' too lightly, since it may be used as a rhetorical device to keep people's aspirations limited and thereby limit their chances to change their lives or even their community for the better. Hence, aspirations can fall into three categories: adapted aspirations, overambitious aspirations, and those in between-safe or achievable aspirations.

In the capability approach (and human development interventions), one could counteract the problem of adapted preferences by stating that we should not be concerned with the capabilities people value, but rather with the capabilities people have reason to value. We thus need to reason about which capabilities we value. This reflexive and critical reasoning entails the potential (although not a guarantee) to counteract adaptation problems in the selection of valuable capabilities. Something similar is needed when counteracting adapted aspirations. Just as it is not sufficient to uncritically register the capabilities that people state they find valuable, one should not uncritically register the aspirations that people voice, and leave it there. Rather, we need to complement the process of aspiration-voicing with additional actions or interventions that challenge people to ask whether their aspirations have been limited by adverse circumstances in which they live, or the unjust or oppressive structures of their society.

In short, the adaptation challenge to using aspirations as part of a human development strategy can be met by complementing the process of voicing and reflecting upon one's aspirations with other activities that raise awareness about the social structures in society, and how these may lead to beliefs that certain things are not possible, when, in fact, they are. These awareness-raising 
activities may draw attention to issues of racial or gender discrimination, or the influence of class and other social structures on our hopes and ambitions. The requirement that people should commit themselves to action would further counter adaptation and over-ambition, as it would require careful consideration about how agency, resources, time and energy would be committed, and would be most likely to evoke an honest and considered response. Because it is furthermore very difficult to really know what people think, and therefore how they adapt, it might be argued that action might be a truer indication of the presence of adaptation than the mere expression of an aspiration. Such awareness-raising and action-oriented activities were part of the action-research programme in Khayeltisha, and will be described in more detail in the following sections.

Do overambitious aspirations also pose a threat to using aspirations in a human development intervention? People from poverty-stricken environments will realize, with trial and error, when their aspirations have been over-ambitious and adapt them to 'realistic' levels, 5 as we all do. It might also be that overambitious aspirations are an example of the optimism which Graham and Hoover (2007) identified in many African contexts. Moreover, the group discussions in the awareness-raising activities will also help to adjust overambitious aspirations back to 'realistic' ones. In that sense, adapted aspirations and overambitious aspirations are both put under pressure to become achievable aspirations, since the group discussion with outside facilitators and mentors should help the participants to get a better sense of what is likely to be an achievable, realistic aspiration. This also means that overambitious aspirations do not pose a threat to the two functions we have outlined for aspirations in capability theory. Firstly, as they would also be capability selecting, they indicate which aspirations people would want to achieve. Secondly, because they pose additional challenges, they would be likely to strongly extend agency.

\section{Khayelitsha: women voicing their aspirations}

In this section the action research programme will be summarized. The design, timelines and outcomes of the programme, which the participating women called Someleze, ${ }^{6}$ is summarized in Appendix 1. ${ }^{7}$ The research was undertaken between 2005 and 2010, although the participating women continue their activities.

The area where the fieldwork was done is Site C, in Khayelitsha, 25 kilometres from the city centre of Cape Town. ${ }^{8}$ The township was founded by the apartheid government in 1983 in order to house people who were streaming to the urban areas in defiance of the notorious 'Influx Control' legislation, designed to keep African people out of urban areas such as the Western Cape. When this legislation was finally repealed in 1986, Khayelitsha grew very fast. It is now a sprawling urban city-within-a-city, with about 1.3 million inhabitants, reasonable infrastructure, and pervasive and high poverty rates (Conradie, 2009, 2013; Du Toit and Neves, 2007; Kane, 2009). The research was designed 
to assess whether a small-scale development programme in which women were invited to voice their life aspirations and to be supported with limited resources in attempting to fulfil their most significant aspiration would increase capabilities and contribute to the reduction of poverty. In order to be able to do this assessment the research included the following aspects:

1. The research was planned as action research (Mouton and Babbie, 2001 pp. 63-66), which entailed the surveying of quantitative household data and qualitative data on the women's aspirations, but also an action component that ran over five years, during which the women were supported with resources and observed in their attempts to pursue their aspirations.

2. The questions on aspirations were carefully formulated to reflect 'beings and doings' as well as 'becomings' (Comim, 2003). One of the questions in the first long survey in phase two reflects this emphasis, and how the element of creative imagination was used to evoke a reflective response:

Imagine that you have a birthday or a celebration many years from now. Imagine you are now older. Imagine you have had a good life, a happy life. Your family and the community have come together to celebrate your birthday and your achievements. Imagine that you also feel very happy and thankful that things have worked out so well for you. What is it that you have achieved in this life you have imagined? What is it that you see in your life when you look back?

3. Much of the literature in the capability approach and the human development paradigm stresses the importance of agency and deliberation when making choices (for example, Crocker, 2008). A programme of skills training and awareness-raising in phase three (see Appendix 1) allowed for reflection and deliberation. It was facilitated by Ina Conradie, two students and four peer mentors from Khayelitsha, 9 for one day a week over eight weeks. The topics discussed included the following:

- Who am I? Understanding myself better.

- How are women restricted by issues of race, class, gender and culture?

- My strengths and growth areas.

- How do economics and politics work? (This discussion referred largely to employment creation and structural constraints to employment for women.)

- Problem-solving and networking.

- Planning for my own programme.

Throughout the following phases, regular meetings were held with opportunities for reflection and support.

4. The planning and conceptualization of the action research as well as the facilitation of the group process was done by Ina Conradie. ${ }^{10}$ She was also responsible for the raising of funds for sewing machines, stoves, and training 
courses for the participating women. As the women had initially decided to approach the action phase collectively, they benefitted more or less equally from the resource allocation. From 2006 to 2007 a second fieldworker, Thandi Guwa, worked with the women in small groups to support their business efforts and to record progress. When they started to build their own businesses the emphasis was on enabling the women to act as autonomously as possible in the pursuit of their own aspirations. The facilitation of the programme was geared towards such individual autonomy whilst dealing with group issues.

5. The voicing of aspirations was initially done individually, to allow every woman to reflect on her individual situation. During phase 5 (Appendix 1), in May 2008, another round of individual interviews on agency and motivation was followed by a collective focus group discussion of aspirations, agency and on cultural constraints to achieving one's aspirations.

6. As observed above, the process of achieving one's aspirations is a dynamic one, which adjusts to changes in one's life situation, material conditions, or to changed insights. As we accompanied the women through this process it was evident that many changed their plans as a result of experiences such as a traffic accident, the loss of a loved one to AIDS or a similar cause, a health setback, or as a result of positive experiences such as moving from a shack into a brick house or having a child graduating at university (Conradie, 2013).

7. Voicing and working on one's aspirations is context dependent, as we maintain above. This means taking into account the socio-economic nature of the area in which the work was undertaken, where employment opportunities are scarce. Only 21.6\% of the women in our household survey had worked for gain for some days of the week (Conradie, 2009) and many people in Site C exist on a survivalist level, leading to a strong reliance on the support of also-struggling family members (Du Toit and Neves, 2009) and on low-level but important government grants (Conradie, 2009; Lund, 2007).

\section{Aspiring to what?}

The action research in Khayeltisha made it clear that poor women have aspirations, are very willing to reflect upon and voice their aspirations, and indeed find that a valuable process. However, we need to ask the question of what these aspirations are referring to: are these women aspiring to more resources, to a happier life, to capabilities and functionings, or to something else? By answering these questions based on the findings of this action research, we can gain additional insights into the question of what it is that poor people aspire to. As Ibrahim (2011) rightly notes, this is a question that has not been sufficiently studied. The essence of the aspirations expressed in this study in both 2006 and 2010 are presented in summary form in Appendix 2. We will now turn to an analysis of these aspirations in order to answer the question of what it is that women in Khayelitsha aspire to. During the skills training sessions in 2006 the women formulated a group goal: to be financially independent and personally autonomous. They felt that this summarized their dream to be in a position to make their own decisions, use their own resources to reach their goals, and not to have to conform to the

\section{https://repository.uwc.ac.za/}


cultural expectation that women should be respectful of and obedient to men (Conradie, 2013). Almost all of the aspirations they voiced afterwards were in line with this central desire-to get the opportunity to do some kind of work, or to fulfil a dream such as providing for their children. The work they wanted to do was also specific in that they wanted to do something satisfying, in line with their own interests. In order to achieve this they also voiced the need for resources such as machines and stoves, for skills training in sewing, catering, healthcare and business training, and for an appropriate workspace. Another central and often repeated aspiration was to assist others who are in need, and to help the community to achieve its social objectives. It can therefore be said that the women aspired to increased functionings and to the capability of independent choice and action, particularly as it would relate to their ability to generate income and contribute to household livelihoods.

\section{Obstaclestoachievingone's aspirations}

Dealing with capability obstacles is central to the achievement of capabilities. In order to achieve the independence they aspired to, almost one-half of the group in both surveys said that they needed money, as it was seen as a crucial means to realize valuable functionings. Another obstacle was seen to be the lack of support from organizations in the community, and from the government, to assist them in their efforts. The reality of their situation is that it is very difficult to become economically independent. The area is far from the central business district and viable markets, Khayelitsha itself is flooded with products that are sold on the street, and they lack access to micro loans or credit. They therefore need some organizational support to get started.

Another obstacle voiced by the women was that of difficult group relationships. In a small group of women working under difficult circumstances with limited resources, conflict is inevitable (Behfar et al., 2011; Brown, 2000). The researcher often acted as facilitator in these conflict situations, and attempted to assist group members to resolve issues themselves, but often members would decide that the group situation was too demanding and decide to rather work on their own.

In a focus group discussion held with 12 of the Someleze women in May 2008 the women stated that their Xhosa culture can be quite restrictive of women, especially in rural areas where a woman has to do as her husband and especially her mother-in-law says. All of the women in the focus group maintained that this lack of personal freedom had been one of the main reasons why they had come to the city. Gender restrictions can therefore act as a capability constraint.

Their lack of education was spelt out as another major constraint to achieving their aspirations. Just less than $60 \%$ of this group had attempted the school-end examination, and only 28.5\% actually passed (Conradie, 2009). Even those who had passed felt that this had not really prepared them for the job market. Only one person commented on the constraint of not speaking English

\section{https://repository.uwc.ac.za/}


well, but this is a much more general problem, as the lack of English language skills acts as a constraint to them fulfilling their aspirations in Cape Town where English is the dominant language.

In striving to gain the capability of independence and the different new functionings associated with that aspiration, the women therefore voiced the need for different capability inputs-resources, space, and skills. They also wanted a sense of personal independence, and the self-confidence and ability to challenge established cultural norms which that required. Although they felt that they had overcome racial oppression, it is clear that their economic opportunities are limited relative to other racial groups even two decades after the end of apartheid, and this forms another capability constraint.

\section{The roles of aspirations in capability enhancement in Khayelitsha}

In the third section, we argued that aspirations can play two distinct roles in human development interventions: a capabilities-selection role, and an agencyunlocking role. Did the action research in Khayelitsha confirm these roles? And did the action research provide any evidence for the presence of adaptation, and the possibilities to counteract adaptation in aspirations?

\section{The capabilities-selecting role of aspirations}

The women in this action research programme seemed to experiment to find the aspirations they wanted to work on. In the initial survey (see Appendix 2) they had a broad 'wish list' of a wide range of aspirations, including having a child, having a wedding, moving out of the area, erecting a tombstone for a deceased relative, and studying at a university. This was followed by extensive discussion and debate on different options and constraints, and when they then had to decide on which aspiration to act, they all chose a collective incomegenerating activity. Thinking through and talking about their aspirations was an effective way of making it clear what the first priority of any poverty-reducing change should be. It seems, however, that the requirement of having to take action on their aspiration is what really helped them to select employment creation as a first priority.

When voicing their aspirations, the women made reference to several capabilities (for details, see Conradie, 2013). If we compare the aspirations they voiced with Nussbaum's list of central human capabilities (2000, pp. 7880), we noticed that none of the voiced aspirations fall outside Nussbaum's list. The women mentioned bodily integrity when discussing the lack of safety for women at night. Being affiliated to others and to show concern for others is a highly regarded value amongst almost all of these women. Most of the women were also very clear that they expected respect from others towards them. When being treated equally was ambiguous, as a woman under certain cultural conditions, they respected the cultural rules while at the same time attempting to change them. Education was mentioned, but instrumentally as a route to improving one's standard of living, rather than as the expression of

\section{https://repository.uwc.ac.za/}


imagination and thought. Regarding practical reason, engaging in the process of formulating aspirations and having regular reflection sessions on these could be said to fall into this category. The women are also highly reflective on their culture, religion and values. Play is a given in this community-people enjoy social gatherings. Political participation and choice is deeply valued, as most people in the group participated in a long and costly struggle to achieve it. Lastly, with regard to material rights, the women wanted to have their own houses and have jobs.

Most of their aspirations related to Nussbaum's (2000, p. 80) 'material control over one's environment'. The other capabilities on Nussbaum's list were not mentioned. For example, living with other species and nature was not ever seen as a priority-women would laugh at the facilitator when this was raised. Livestock is seen as wealth, as food, and as a source of sacrifice in communicating with one's ancestors. Yet this does not, of course, imply that these capabilities are never valuable, and hence that these women suffer from adapted aspirations since they do not mention these capabilities. Rather, it is much more plausible to understand the aspirations that are voiced as an indication of where to put priorities in the human development intervention; for this particular group of women, who are living in a certain area under a certain set of social, political and economic structures, clear priorities can be demarcated as part of a human development intervention. In sum, the results from the Khayelitsha action research clearly illustrated the capabilities- selecting role of the voicing of aspirations, which capabilities to focus on, and also which capabilities the surveyed women do not value.

\section{The agency-unlocking role of aspirations}

How about the second role of aspirations for human development strategies, the agency-unlocking role? The action research in Khayelitsha clearly demonstrated this role. Our evidence for this is two-fold. First, we observed that the women who took part in the Someleze programme took the initiative to set up the Someleze Women's Centre, from which some of them conduct their activities. In addition, several women who did not stay in Someleze also took action to realize their aspirations. Diyeketso, for example, who had moved out of Site C, realized the aspiration that she had voiced in the first aspirations interview by setting up a catering business in her new home. Francis started out in the sewing group but then decided to sew on her own and to also concentrate on the care of AIDS orphans in the area, and is now in the process of setting up a care centre. Of course, it is impossible to know what initiatives these women would have taken if the action research had not been set up; in principle, it is possible that they would have undertaken the same initiatives. Yet given that such initiatives are rare by women living in the same area who were not taking part in Someleze, and given that the women of the programme did not take these initiatives in the past, it seems very unlikely that some of these initiatives would have been undertaken without the intervention of Someleze. 
However, our second type of supporting data provides independent evidence for the agency-unlocking role of the aspiration-voicing process. That evidence is the interviews with the women in April and May 2010, when they were asked what important choices and decisions they had made in the last four years. ${ }^{11}$ Twenty-three of the 25 women had shown elements of agency and initiative in pursuing their aspirations. Sixteen of these expressed the decision to exercise agency quite strongly. Some of these responses were as follows:

I promised myself I would continue with the bed and breakfast, although it was not always easy-the problem is money. (Patricia, interview, 29 May 2010)

I decided to be part of the solution by joining Someleze, being part of the sewing group. I became a street committee member and I became a SANCO [civic association] committee member. My choices have not changed, I'm just adding and I am achieving them. (Francis, interview, 9 April 2010)

I decided to stay focussed-I want to be a nurse, then be independent. (Ntombizodwa, interview, 22 May 2010; she became a paid health visitor after this interview)

In the companion paper (Conradie, 2013), we compared the individual aspirations of each of the 25 women with the key outcomes of their work on their aspirations over five years. This is used to ask the question of whether their functionings and capabilities had increased as a result of the deliberate work on their aspirations. For the 23 women who had made different efforts, capabilities had increased. Whether the women would be able to repeat these new functionings without assistance from a facilitator in future is difficult to assess. The few who had made major breakthroughs undoubtedly would, but for most of the women it has become clear that this is not necessarily a linear process with clear and uni-directional progress. Looking at the success rate of the women in terms of achieving their aspirations overall and at their verbal responses, it is striking that those who said that they were determined to succeed, and who kept trying one thing after another, did eventually change their own situation, even if only in small but ongoing ways. This supports our point that aspirations are not formulated or achieved at once, but in a continuous process that requires perseverance on the part of the participants. It also indicates that success in achieving their aspirations rested in the first place on the amount of active agency in which they engaged, supporting the claim that the work on aspirations is agency-unlocking.

\section{The challenges of adapted aspirations}

The list of initial aspirations voiced by the women included a broad range of aspirations (see Appendix 2). In these interviews they clearly experimented with a range of possibilities as they were not yet clear on what resources would be available or what their own capacity or limitation might be. When later in the process they had to commit to one aspiration, they limited their choices to four specific areas of employment creation, namely sewing, catering and having a

\section{https://repository.uwc.ac.za/}


guesthouse, home-based care work and hair salons. This confirms Elster's (1983, pp. 112-114) argument that experimentation can lead to more informed preferences and hence lift adaptation from preferences and aspirations. Whereas the expression of aspirations had been individual up to that point, it furthermore now became collective, and led to collective action for some. They also still experimented with their own individual level of aspiration within the collective action. Patricia, who initially wanted a guesthouse for tourists, compromised by doing catering in her own area when the guesthouse proved difficult to set up. This experimentation, however, did not show signs of 'habituation or resignation', which is how Elster (1983, p. 113) understands adaptation. To the extent that the women in this study were actively and deliberately engaged in selecting and working on their capabilities, there had not been a socialized or resigned response, and hence there had not been adaptation. It thus seems plausible to believe that adaptation was prevented from the start of the programme by the active capability selection and agency required of the women who were taking part.

There were, however, structural and institutional constraints over which they have limited control, such as their particular educational background, their race, their gender and certain cultural constraints which do affect the eventual functionings which these women will experience, and also the real opportunities that are available to them (hence their capabilities) (Conradie, 2013). These constraints did not seem to affect the aspirations, but do constrain the lives which these women can lead.

\section{Limitations of the research}

There are a number of clear limitations to this research programme. A fuller analysis can be found in Conradie (2013), yet it is important to highlight two limitations of the action research programme here. First, the field researcher was an outsider in terms of culture, language and race, which meant that a translator was always needed and that many of the subtle dynamics associated with a different culture might have been overlooked. She is nevertheless a South African with work experience in the area. Secondly, the programme included a transfer of some resources in this resource-deprived area, which meant that some women might have joined to see to what extent they would benefit from the project, rather than to work on their own aspirations.

Note also that we cannot conclude based on the research presented in this article that adaptation never occurs, or would not have occurred if the women had not taken part in the action research programme. We can only conclude that the action research programme conducted in Kayelitsha did not provide any evidence for adaptation in the aspirations that were formulated after taking part in a process that aimed to counter possible adaptation bias, and that the evidence we have confirms the two theoretical hypotheses that we formulated. In Ray's (2003) terms, the aspirations of the women made it clear that they have a significant aspirations gap, and hence they did not show adaptation in the sense of having a very small or negligible adaptation gap. Still, if we were to compare the absolute levels of aspirations of these women with those of others, 
it is very likely that these absolute levels of aspirations would be lower (as Burchardt [2009] showed for the United Kingdom). These women want, just as their better-off fellow citizens, to climb a few steps on the aspirations staircase; yet they are currently positioned much lower on that staircase.

\section{Conclusions}

The question we posed earlier was whether human development intervention can benefit from deliberate work on aspirations. That would depend on whether work on aspirations would increase capabilities. We have theoretically argued that aspirations may have a capabilities-selecting role and an agency-selecting role. Adaptation may pose challenges for these two roles, but one would expect that if the formation and voicing of aspiration is part of a small-scale intervention programme that also includes deliberation and awareness-raising, then the possible threat of adaptation may be overcome. Based on fieldwork in Khayelitsha we have found that women seemed to experiment to find the correct level of their aspirations. Only when they had to act on these did they focus on creating concrete employment opportunities. It therefore seems that the process of reflection and action on aspirations assisted the selection of aspirations, and thus capabilities, evoked active agency, contributed to the countering of adaptation and was a necessary but not sufficient component of these women's development. We conclude that the action research in Khayelitsha provides empirical support for our hypotheses that aspirations can be capability selecting and agency unlocking. It is important to stress the limited scope and ambition of this article. We have not tried to argue that work on aspirations is a panacea for poverty-reduction programmes. We have not talked about the role of aspirations at a larger scale; for example, the role that aspirations may play in revolutions or large-scale civil protests. Neither have we discussed some of the other important questions, such as whether it is allthings-considered ethical to do work on aspirations if one cannot also contribute to the delivery of the capability inputs and the lifting of some capability constraints, since one may only create frustrations. There are also important issues of fairness related to working on aspirations both on a smallscale as well as in larger human development interventions; for example, that those who have the most ambitious aspirations, or those who are most persuasive in expressing them, will be allocated most resources. We hope that these questions will be addressed in further research.

\section{Acknowledgements}

We would like to thank the women who took part in the action-research described in this paper, Constanze Binder, two anonymous referees and an associate editor of this journal for comments on an earlier version, and SANPAD for research funding. 


\section{Notes}

1. This is a companion paper to Conradie (2013), where we discuss in more detail the action research programme on which the empirical part of this paper is based. The companion paper focuses on the assessment of whether there is an enhancement of functionings and capabilities among the participants in the research programme, while this paper develops a theoretical hypothesis, which is confirmed by the findings from the programme.

2. A township is a residential area for Black citizens in South Africa that was created as a part of the Apartheid ideology that different races should live separately. Townships are often situated on the periphery of a city or town.

3. See Clark (2012b) for a taxonomy of different ways in which the term 'adaptation' has been used.

4. The notion of '(seemingly) overambitious aspirations' is what Clark (2009, p. 23) calls 'upwards adjusting aspirations'. We agree with the importance of the phenomenon that Clark describes, but prefer our terminology, since those overambitious aspirations do not adapt to objective circumstances in the life of the poor person herself. Overambitious aspirations are rather fuelled by the lives of people who are much better off, such as those who live more affluent lives within the same geographical area, or by the lives of middle-class and upper-class people that are screened on television. To use Ray's (2003) terminology: these middle-class and upper-class people are within their 'aspiration window'.

5. Following Ray (2003), one could understand 'realistic' aspirations as those where the 'aspiration gap' (hence the distance between one's situation now and the goals one hopes to achieve) is not so wide that it cannot be reached with the effort or investment that the person can maximally afford.

6 Someleze is a Xhosa word that means 'We strengthen each other'.

1. The research was sponsored by SANPAD, the South African Netherlands Programme for

Alternatives in Development. Ina Conradie was the field researcher/facilitator and Ingrid Robeyns was the Dutch research partner between 2007 and 2010. Robeyns was not engaged in the fieldwork; she only helped in the design of the survey and engaged in discussions of the interpretation of the results.

2. Site $\mathrm{C}$ is a section or suburb of Khayelitsha.

3. Four successful businesswomen from Khayelitsha took part in the training programme as group facilitators. Peer mentoring is a strategy that has been used in education and healthcare with some success (Le Roux et al., 2010). The peer mentors were inspirational, as they proved that it was possible to come from the same background, and nevertheless to achieve one's aspirations.

4. Ina Conradie has been involved in development education, training and facilitation for three decades.

5. See Appendix 1, phase 5 for more information on the selection of these women. 


\section{References}

Alkire, S. (2002) Valuing Freedoms. Sen's Capability Approach and Poverty Reduction, Oxford University Press, Oxford.

Alkire, S. (2005) 'Why the capability approach?', Journal of Human Development, 6(1), pp. 115-133.

Alkire, S. (2008) 'Choosing dimensions: The capability approach and multidimensional poverty', in N. Kakwani and J. Silber (Eds) The Many Dimensions of Poverty, Palgrave-Macmillan, London, pp. 89-119.

Appadurai, A. (2004) 'The capacity to aspire: Culture and the terms of recognition', in V. Rao and M. Walton (Eds), Culture and Public Action, Stanford University Press, Stanford, Calif., pp. 59-84.

Behfar, K., Mannix, E., Peterson, R. and Trochim, W. (2011) 'Conflict in small groups: The meaning and consequences of process conflict', Small Group Research, 42(2), pp.127-176. Bernard, T., Taffesse, A. S. and Dercon, S. (2008) Aspirations Failure and Well-being Outcomes in Ethiopia: Towards an Empirical Exploration, mimeo, [http://www.iig.ox.ac.uk/output/ presentations/pdfs/E13-Aspirations-and-WellBeing-Outcomes-inEthiopia.pdf], accessed 8 November 2012.

Brown, R. (2000) Group process: Dynamics Within and Between Groups, 2nd edition, Blackwell, Malden, MA.

Burchardt, T. (2009) 'Agency goals, adaptation and capability', Journal of Human Development, 10(1), pp. 3-19.

Clark, D. (2009) 'Adaptation, poverty and well-being: Some issues and observations with special reference to the capability approach and development studies', Journal of Human Development and Capabilities, 10(1), pp. 21-42.

Clark, D. (Ed.) (2012a) Adaptation, Poverty and Development. The Dynamics of Subjective Well-being, Palgrave Macmillan, Basingstoke.

Clark, D. (2012b) 'Adaptation and development-Issues, evidence and policy relevance', in D. Clark (Ed.) Adaptation, Poverty and Development. The Dynamics of Subjective Wellbeing, Palgrave Macmillan, Basingstoke, pp. 131.

Comim, F. (2003) Capability Dynamics: The Importance of Time to Capability Assessments, [http://cfs.unipv.it/sen/papers/Comim.pdf], accessed 17 February 2012.

Conradie, I. (2009) SANPAD Research Report. Enhancing Selected Life-skills as a Key to Development: Addressing the Aspirations of Poor Women in Khayelitsha (2006-2009), Institute for Social Development, University of the Western Cape, Cape Town.

Conradie, I. (2013) Can deliberate efforts to realise aspirations increase capabilities? A South African case study, Oxford Development Studies, 41(3), pp. 189-219.

Crocker, D. A. (2008) Ethics of Global Development: Agency, Capability and Deliberative Democracy, Cambridge University Press, Cambridge.

Douglas, M. (2004) 'Traditional Culture - Let's Hear No More About It', in V. Rao and M. Walton (Eds), Culture and Public Action, Stanford University Press, Stanford, Calif., pp. 85-109. 
Du Toit, A. and Neves, D. (2007) 'In search of South Africa's "second economy": Chronic poverty, economic marginalisation and adverse incorporation in Mt. Frere and Khayelitsha', PLAAS Working Paper No. 1, University of the Western Cape and University of Manchester, Chronic Poverty Research Centre.

Du Toit, A. and Neves, D. (2009) 'Informal social protection in post-apartheid migrant networks: Vulnerability, social networks and reciprocal exchange in the Eastern and Western Cape, South Africa', PLAAS Working Paper No. 2, University of the Western Cape.

Elster, J. (1983) Sour Grapes. Studies in the Subversion of Rationality, Cambridge University Press, Cambridge.

Graham, C. and Hoover, M. (2007) 'Optimism and poverty in Africa: Adaptation or a means to survival?', Afrobarometer Working Paper No. 76, November, [http://www.afrobarometer.org/publications/working-papers/item/123optimism-and-poverty-in-africa-adaptation-or-a-means-to-survival], accessed 15 August 2013.

Ibrahim, S. (2006) 'From individual to collective capabilities: The capability approach as a conceptual framework for self-help', Journal of Human Development, 7(3), pp. 397-416.

Ibrahim, S. (2011) 'Poverty, aspirations and wellbeing: afraid to aspire and unable to reach a better life-Voices from Egypt', BWPI Working Paper 141, [http://www.bwpi.manchester. ac.uk/resources/Working-Papers/bwpi-wp14111.pdf], accessed 16 November 2012.

Kane, D. (2009) 'Multi-dimensional forms of poverty experienced by unemployed HIV-positive mothers living in Khayelitsha', CSSR Working Paper No. 243, University of Cape Town.

Khader, S. (2009) 'Adaptive preferences and procedural autonomy', Journal of Human Development and Capabilities, 10(2), pp.169-187.

Le Roux I. M., et al. (2010). 'Home visits by neighborhood Mentor Mothers provide timely recovery from childhood malnutrition in South Africa: Results from a randomized controlled trial', Nutrition Journal, 9, p. 56.

Lund, F. (2007) Changing Social Policy: The Child Support Grant in South Africa, HSRC Press, Cape Town.

Mouton, J. and Babbie, E. (2001) The Practice of Social Research, Oxford University Press, Oxford.

Nussbaum, M. (2000) Women and Human Development: The Capabilities Approach, Cambridge University Press, Cambridge.

Ray, D. (2003) Aspirations, Poverty and Economic Change, [http://www.econ.nyu.edu/user/ debraj/Papers/povaspo1.pdf], accessed 16 November 2012.

Robeyns, I. (2005a) 'The capability approach: A theoretical survey', Journal of Human Development, 6(1), pp. 93-114.

Robeyns, I. (2005b) 'Selecting capabilities for quality of life measurement', Social Indicators Research, 74, pp. 191-215.

Robeyns, I. (2010) 'How can the capability approach be used to serve marginalized communities at the grassroots level?', in F. Apffel-Marglin, S. Kumar and A. Mishra (Eds), Interrogating Development. Insights from the Margins, 
Oxford University Press, New Delhi, pp. 243-261. Sen, A. (1985a) 'Well-being, agency and freedom: The Dewey Lectures 1984', Journal of Philosophy, 82(4), pp. 169-220.

Sen, A. (1985b) Commodities and Capabilities, Oxford University Press, New Delhi (first published by North Holland, Amsterdam).

Sen, A. (1992) Inequality Reexamined, Clarendon Press, Oxford. Sen, A. (1999) Development as Freedom, Knopf, New York.

Teschl, M. and Comim, F. (2005) 'Adaptive preferences and capabilities: Preliminary considerations', Review of Social Economics, 63(2), pp. 229-247.

Tiwari, M. and Ibrahim, S. (2012) 'Sustainable human development at the grass roots: Different contexts, similar ingredients?', Oxford Development Studies, 40(1), pp. 69-85. 
Appendix 1. Action research programme: timelines and activities

\begin{tabular}{|c|c|c|c|c|}
\hline Phase & Dates & Number of women & Activities & Other information \\
\hline Phase 1 & February 2006 & $\begin{array}{l}N=104 . \text { All invited } \\
\text { to next phase }\end{array}$ & $\begin{array}{l}\text { General survey and long } \\
\text { aspirations interview with } \\
25 \text { qualitative questions. } \\
\text { Interviews conducted by } \\
\text { sets of two Xhosa-speaking } \\
\text { researchers }\end{array}$ & Material processed by SPSS \\
\hline Phase 2 & $\begin{array}{l}\text { May-August } \\
2006\end{array}$ & $\begin{array}{l}50 \text { turned up for life- } \\
\text { skills course }\end{array}$ & $\begin{array}{l}\text { Eight-week life-skills training } \\
\text { course, one day per week, } \\
\text { on personal skills; social } \\
\text { analysis on race, class, } \\
\text { gender and culture, using } \\
\text { their own life-histories. } \\
\text { Input on aspirations, final } \\
\text { choice made: employment } \\
\text { creation groups chosen: } \\
\text { catering, sewing, hair } \\
\text { dressing, community care }\end{array}$ & $\begin{array}{l}\text { Discussions and reflection } \\
\text { countered adaptation of } \\
\text { aspirations }\end{array}$ \\
\hline Phase 3 & $\begin{array}{l}\text { September } \\
\text { 2006- } \\
\text { August } 2007\end{array}$ & 40 remained & $\begin{array}{l}\text { Fundraising for employment } \\
\text { groups. Women worked in } \\
\text { small groups on their } \\
\text { activities. Regular monthly } \\
\text { meetings with whole group }\end{array}$ & $\begin{array}{l}\text { Raised } \mathrm{R} 100,000 \text { for } \\
\text { training and equipment }\end{array}$ \\
\hline Phase 4 & $\begin{array}{l}\text { September } \\
2007- \\
\text { November } \\
2009\end{array}$ & 40 & $\begin{array}{l}\text { Sewing group: received } \\
\text { machines and training, } \\
\text { sewed on contracts. } \\
\text { Catering group: training- } \\
\text { group split due to conflict. } \\
\text { Home based care group: } \\
\text { two different training } \\
\text { courses, started care } \\
\text { activities }\end{array}$ & $\begin{array}{l}\text { Two containers donated, } \\
\text { also funds for a centre }\end{array}$ \\
\hline Phase 5 & $\begin{array}{l}\text { April-May } \\
2010\end{array}$ & $\begin{array}{l}19 \text { women } \\
\text { interviewed, six } \\
\text { added, } 25 \text { analysed } \\
\text { in Conradie (2013) }\end{array}$ & $\begin{array}{l}24 \text { women were from the } \\
\text { original group from } 2006 \text {, } \\
\text { while Esihle joined in } 2008 \text {. } \\
19 \text { could betraced and were } \\
\text { available for interviews. Six } \\
\text { other very active members } \\
\text { were added because their } \\
\text { situation was known to } \\
\text { us-one chose not to be } \\
\text { interviewed, two are } \\
\text { deceased, one now fully } \\
\text { employed, one left for the } \\
\text { Eastern Cape, one had a } \\
\text { stroke }\end{array}$ & $\begin{array}{l}\text { Only four of this group } \\
\text { work with the new } \\
\text { members in the Someleze } \\
\text { centre, the others work } \\
\text { on their own or in other } \\
\text { groups }\end{array}$ \\
\hline
\end{tabular}


Appendix 1. (Continued)

\begin{tabular}{lllll}
\hline Phase & Dates & Number of women & Activities & Other information \\
\hline Phase $6 \quad 2010$ onwards & 30 & $\begin{array}{c}\text { Centre used daily, although } \\
\text { many of the women there } \\
\end{array}$ & $\begin{array}{l}\text { Pre new to the group. } \\
\text { arame is ongoing, will } \\
\text { function more } \\
\end{array}$ & independently \\
& & volunteers & \\
\hline
\end{tabular}

Note: $N=103$ women; some multiple responses.

\section{Appendix 2. Responses to 2006 and 2010 aspirations surveys}

2006 aspirations survey responses

To have money: 25

To have a job: 22

To have a better house: 15

To have a business: 14

Sewing and designing: 9

To have a car: 8

To study: 8

To have her own hair salon: 7

A better life for her children: 6

To build a house in the Eastern Cape: 6

To be financially independent: 5

Wants to be a nurse: 1 (four more said this in different forums)

To do catering: 2

To have a bed-and-breakfast guesthouse: 2

To be a social worker: 2

To do community care: 2

To live outside Site C, or Khayelitsha, in the 'suburbs': 3

To erect a tombstone and do a traditional ceremony for deceased relatives: 1

To care for AIDS orphans: 1

To be a policewoman: 1

To have a care job: 1

Wants to be a professional, well-known hairdresser, own property, have an independent relationship with a man: 1 A wedding, if her business is successful: 1

Information technology skills: 1

To be a famous actor: 1

To share with others: 1

To have a child: 1

To have nice things: 1

To have everything I need: 1

Responses to aspirations survey 2010 ( $n=25$; also multiple responses)

To succeed at the work they had undertaken: 13

To ensure their children are better off than before: 2 (already succeeded)

To help others: 8

To become a nurse: 5

To be independent, financially and otherwise: 5

Note: $N=103$ women; some multiple responses 